\title{
Light-Addressable Potentiometric Sensors using ZnO Nanorods as the Sensor Substrate for Bioanalytical Applications
}

Ying $\mathrm{Tu}^{\dagger}$, Norlaily Ahmad ${ }^{\dagger}$ §, Joe Briscoe ${ }^{\dagger}$, De-Wen Zhang ${ }^{\dagger, ~} \neq *$ and Steffi Krause $^{\dagger *}$

s.krause@qmul.ac.uk

†. Materials Research Institute and School of Engineering and Material Science, Queen Mary University of London, Mile End Road, London, E1 4NS, U.K.

dewen.zhang@qmul.ac.uk

‡. Institute of Materials, China Academic of Engineering Physics, Jiangyou, 621908, Sichuan, China.

$\S$ Centre of Foundation Studies, Universiti Teknologi MARA, Cawangan Selangor, Kampus Dengkil, 43800 Dengkil, Malaysia

\begin{abstract}
Light-addressable potentiometric sensors (LAPS) are of great interest in bioimaging applications such as the monitoring of concentrations in microfluidic channels or the investigation of metabolic and signaling events in living cells. By measuring the photocurrents at electrolyte-insulator-semiconductor (EIS) and electrolyte-semiconductor structures, LAPS can produce spatiotemporal images of chemical or biological analytes, electrical potentials and impedance. However, its commercial applications are often restricted by their limited AC photocurrents and resolution of LAPS images. Herein, for the first time, the use of 1D semiconducting oxides in the form of $\mathrm{ZnO}$ nanorods for LAPS imaging is explored to solve this issue. A significantly increased AC photocurrent with enhanced image resolution has been achieved based on $\mathrm{ZnO}$ nanorods, with a photocurrent of $45.7 \pm 0.1 \mathrm{nA}$ at a light intensity of $0.05 \mathrm{~mW}$, a lateral
\end{abstract}


resolution as low as $3.0 \mu \mathrm{m}$ as demonstrated by images of a PMMA dot on $\mathrm{ZnO}$ nanorods and a pH sensitivity of $53 \mathrm{mV} / \mathrm{pH}$. The suitability of the device for bioanalysis and bioimaging was demonstrated by monitoring the degradation of a thin poly(ester amide) film with the enzyme a-chymotrypsin using LAPS. This simple and robust route to fabricate LAPS substrates with excellent performance would provide tremendous opportunities for bioimaging.

Imaging technology is crucial to many disciplines and is generally classified as optical imaging, electronic imaging or a combination of both. $A$ light-addressable potentiometric sensor ${ }^{1-5}$ is a semiconductor-based chemical device with applications in the fields of chemistry, materials science, biology and medicine. First proposed by Hafeman et al. in 1988, ${ }^{2}$ LAPS belongs to the family of field-effect sensors that use an electrolyte-insulator-semiconductor (EIS) structure, in which the sensing surface of the insulating layer is in contact with the solution to be analyzed. ${ }^{6-9}$ With LAPS, chemical images can be generated that visualize the concentration distribution above the sensor substrate. This light addressability can be used to detect chemical or biological analytes, such as $\mathrm{pH}$, ions, redox pairs, organs, tissues, cells, and enzymatic reactions by recording photocurrents generated locally in the semiconductor with a focused, intensity-modulated light source. ${ }^{6-12}$ The response of LAPS is based either on a change in the surface potential of the insulator or a change in the electrical impedance.

An important aspect in LAPS is to achieve good lateral resolution and measurement speed to visualize the spatial distribution of analytes in the form of 2-D imaging. ${ }^{13-17}$ It was determined that two main factors limit the spatial resolution, which are (i) the lateral diffusion length of minority charge carriers out of the illuminated area in the semiconductor and (ii) the quality of the light focus for charge carrier excitation. A resolution of $1.5 \mu \mathrm{m}$ was achieved using a focused $405 \mathrm{~nm}$ laser beam on a silicon on sapphire (SOS) substrate. ${ }^{14}$ Using a two-photon effect with a femtosecond laser at $1250 \mathrm{~nm}$ for charge carrier 
generation improved the resolution to $0.8 \mu \mathrm{m}$ on boron-doped SOS substrates, which is the best resolution reported to date. ${ }^{13}$ However, given the high cost and complex surface treatment of currently used substrates, much of the studies in LAPS have remained at laboratory research level.

Previous studies have investigated numerous semiconductor materials in the EIS structure for LAPS including $\mathrm{Si}^{14}{ }^{14} \mathrm{GaN},{ }^{18} \mathrm{NbO}_{x},{ }^{19}$ and $\mathrm{TiO}_{2} .{ }^{20}$ Recently, an indium tin oxide (ITO) surface without an insulator was reported for LAPS as well as scanning photo-induced impedance microscopy (SPIM) imaging. ${ }^{21}$ The absence of an insulator layer in a LAPS platform has a number of advantages: (i) The sensitivity of the sensor surface for samples with charge and impedance is increased; (ii) The device is not only sensitive to potential and impedance changes, but can also record redox processes; (iii) There is no limitation to the modification of semiconductor surface by functionalization and (iv) the device assembly process is greatly simplified and low cost.

In this study, $\mathrm{ZnO}$ nanorods were used for LAPS measurements without the presence of an insulator. Given that $\mathrm{ZnO}$ has high electron mobility, high thermal conductivity, direct wide band gap, large exciton energy, ease of synthesis and low cost, it has been shown to be a promising semiconductor material for a wide range of applications, including energy harvesting systems, ${ }^{22-24}$ chemical and biological sensors, ${ }^{25-29}$ and photocatalysts. ${ }^{30,31}$ Nanostructured $\mathrm{ZnO}$, for example as nanorods, is currently attracting significant attention given that it increases the active surface sites, improves charge generation efficiency, and reduces the cost as well as simplifying the processing. The $\mathrm{n}$-type conductivity caused by oxygen vacancies in $\mathrm{ZnO}$ makes it possible to excite charge carriers with light with photon energy less than its bandgap of $3.3 \mathrm{eV}^{32,33}$ In this work, $\mathrm{ZnO}$ nanorods without an insulator layer, are excited to generate AC photocurrents with a $405 \mathrm{~nm}$ diode laser that is a commonly used light source in LAPS. The morphology, optical properties and crystal structure of $\mathrm{ZnO}$ nanorods synthesized by one of the simplest and cheapest methods of aqueous synthesis were investigated. Photocurrent response, $\mathrm{pH}$ sensitivity, 2-D photocurrent images, the effect of the $\mathrm{ZnO}$ 
morphology on the lateral resolution and a disposable biosensor using $\mathrm{ZnO}$ nanorods were examined with a LAPS setup that is shown in Figure 1.

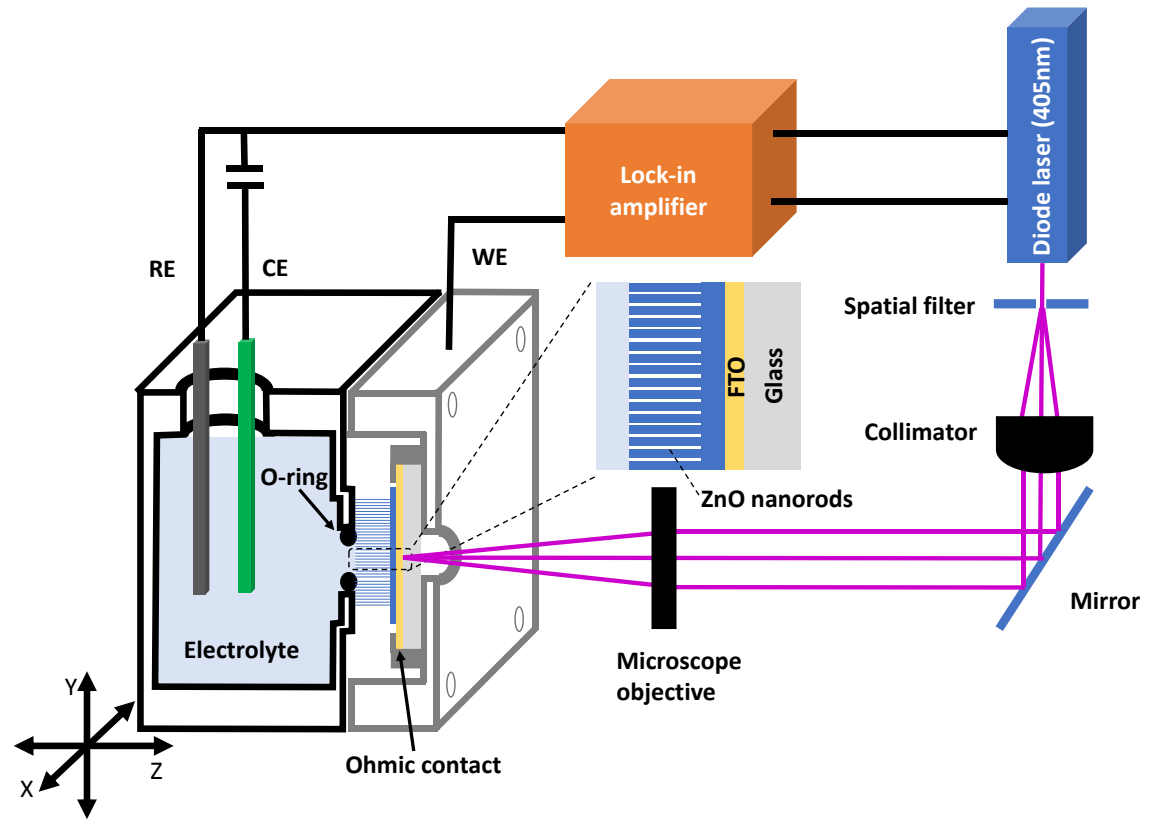

Figure 1. LAPS setup consisting of a diode laser, an electrochemical cell, a positioning system that can move the electrochemical cell with respect to the laser beam and a lock-in amplifier.

\section{Experimental Section}

ZnO nanorods synthesis and characterization: $\mathrm{ZnO}$ nanorods were synthesized on FTO-coated glass $(1 \mathrm{~cm} \times 1 \mathrm{~cm}, 15 \Omega / \mathrm{sq}$, Solaronix SA Switzerland). ${ }^{34-36}$ The substrate was cleaned by ultra-sonication using acetone (VWR Chemicals, 100\%) and then 2-propanol (VWR Chemicals, 100\%) for 15 min. A seed layer of zinc acetate (Sigma-Aldrich, $\geq 98 \%$ ) was coated on the substrate from a $5 \mathrm{mM}$ solution in ethanol. The solution was dropped on the substrate and dried by nitrogen, followed by annealing in air at $350{ }^{\circ} \mathrm{C}$ for 25 min. A thin crystallized $\mathrm{ZnO}$ seed layer was formed after annealing. The seeding process was repeated three times. The substrate was suspended face-down in a jar with a solution consisting of equal concentrations of $25 \mathrm{mM}$ hexamethylenetetramine (HMT, Sigma-Aldrich, $\geq 99 \%$ ) and zinc nitrate (Sigma-Aldrich, 99\%). The $\mathrm{ZnO}$ film was produced in a $100 \mathrm{mM}$ equivalent molar HMT and zinc nitrate solution. In both cases, the jar was placed into a 
pre-heated oven (Memmert, Co. KG) for $24 \mathrm{~h}$ at $90{ }^{\circ} \mathrm{C}$. Afterward, the substrate was washed with distilled water and dried with nitrogen. The $\mathrm{ZnO}$ nanorods and the $\mathrm{ZnO}$ film were annealed in a box furnace (Lenton, UK) at $350{ }^{\circ} \mathrm{C}$ in air for $1 \mathrm{~h}$. The surface and cross-sectional morphology of $\mathrm{ZnO}$ nanorods and film were examined using a scanning electron microscope (SEM, FEI Inspect F). Absorption spectra of $\mathrm{ZnO}$ were measured by UV-Vis spectrometer (Perkin Elmer, Lamda 950). High resolution X-ray photoelectron spectroscopy (XPS) was carried out by Thermo Scientific K-Alpha ${ }^{+}$. XPS data were analyzed by CasaXPS ${ }^{\mathrm{TM}}$ software with a calibrated C 1s peak of 284.8 $\mathrm{eV}$.

Linear sweep voltammetry: An Autolab PGSTA30/FRA2 (Windsor Scientific Ltd., UK) was used to carry out linear sweep voltammetry (LSV, scan rate was $5 \mathrm{mV} / \mathrm{s}$ ) in $0.2 \mathrm{M} \mathrm{Na}_{2} \mathrm{SO}_{4}$; a platinum electrode and a $\mathrm{Ag} / \mathrm{AgCl}$ electrode were used as counter and reference electrodes, respectively. A diode laser $(\lambda=405$ $\mathrm{nm}$, max $500 \mathrm{~mW}$ ) was used as the light source. The illumination was chopped in $10 \mathrm{~s}$ intervals.

LAPS and SPIM measurement: The LAPS setup is shown in Figure $1 .^{13}$ The electrochemical cell was mounted on an M-VP-25XL XYZ positioning system (50 nm motion sensitivity, Newport, UK) to adjust the sample position for 2-D $X Y$ scans and focusing in the $Z$ direction. An electronically modulated, focused diode laser LD1539 (Laser 2000, $\lambda=405 \mathrm{~nm}$, max $50 \mathrm{~mW}$, focused spot diameter $\approx 1 \mu \mathrm{m}$ ) was used as the light source for LAPS measurement. AC photocurrents were measured with an EG\&G 7260 lock-in amplifier. A platinum electrode and $\mathrm{a} \mathrm{Ag} / \mathrm{AgCl}$ electrode acted as counter and reference electrodes, respectively. The electrolyte was $10 \mathrm{mM}$ pH 7.4 phosphate-buffered saline (PBS) solution. Poly(methyl methacrylate) (PMMA, Aldrich, average M.W. 120000) was dissolved to form a $11 \mathrm{wt} \%$ solution in methoxybenzene (Sigma-Aldrich, 99\%). A drop of PMMA solution was deposited on $\mathrm{ZnO}$ nanorods and dried without assistance at room temperature.

Enzymatic degradation of a thin polymer film: The synthesis and purification of the polymer, poly(ester amide), was described by Sumner et 
al. ${ }^{37} \mathrm{a}$-Chymotrypsin, type II, from bovine pancreas with activity of 40 units $/ \mathrm{mg}$ was supplied by Sigma-Aldrich. A $1 \mu \mathrm{L}$ drop of solution of $200 \mathrm{mg} / \mathrm{mL}$ poly(ester amide) in chloroform was deposited on the surface of $\mathrm{ZnO}$ and dried overnight without assistance. A $100 \mathrm{mM}$ a-chymotrypsin solution in a $\mathrm{pH} 7.3$ buffer was kept in $-20{ }^{\circ} \mathrm{C}$ in prior to use. During the degradation, LAPS photocurrent images in a range of $3000 \mu \mathrm{m}$ with a step size of $30 \mu \mathrm{m}$ were taken every $2 \mathrm{~h}$ at $1.5 \mathrm{~V}$ with a focused laser modulated at $10 \mathrm{~Hz}$. The area of the polymer was calculated using ImageJ, version 1.51k.

\section{Results and discussion}

\section{ZnO nanorod characterization}

An array of $\mathrm{ZnO}$ nanorods formed uniform and well-oriented hexagonal shapes with $4.03 \pm 0.025 \mu \mathrm{m}$ length and $78.4 \pm 2.7 \mathrm{~nm}$ diameter (Figures $2(A)$ and $(B)$ ) resulting in an aspect ratio of $51 .{ }^{34}$ Optical properties of $\mathrm{ZnO}$ nanorods were investigated by UV-Vis absorption spectroscopy (Figure 2(C)). The inset Tauc-plot shows a direct band gap of $3.34 \mathrm{eV}$. The absorption coefficient of the $\mathrm{ZnO}$ nanorods at a wavelength of $405 \mathrm{~nm}$ was determined to be $288 \mathrm{~cm}^{-1}$, i.e. the laser light used for photocurrent excitation illuminates the entire depth of the film. Defects caused by oxygen vacancies in the oxygen deficient regions were confirmed with an $\mathrm{O} 1 \mathrm{~s}$ peak at $531.3 \mathrm{eV}$ in XPS (Figure S-1) ${ }^{38} \mathrm{~A}$ more detailed characterization of the $\mathrm{ZnO}$ nanorods is given elsewhere. ${ }^{34}$ 

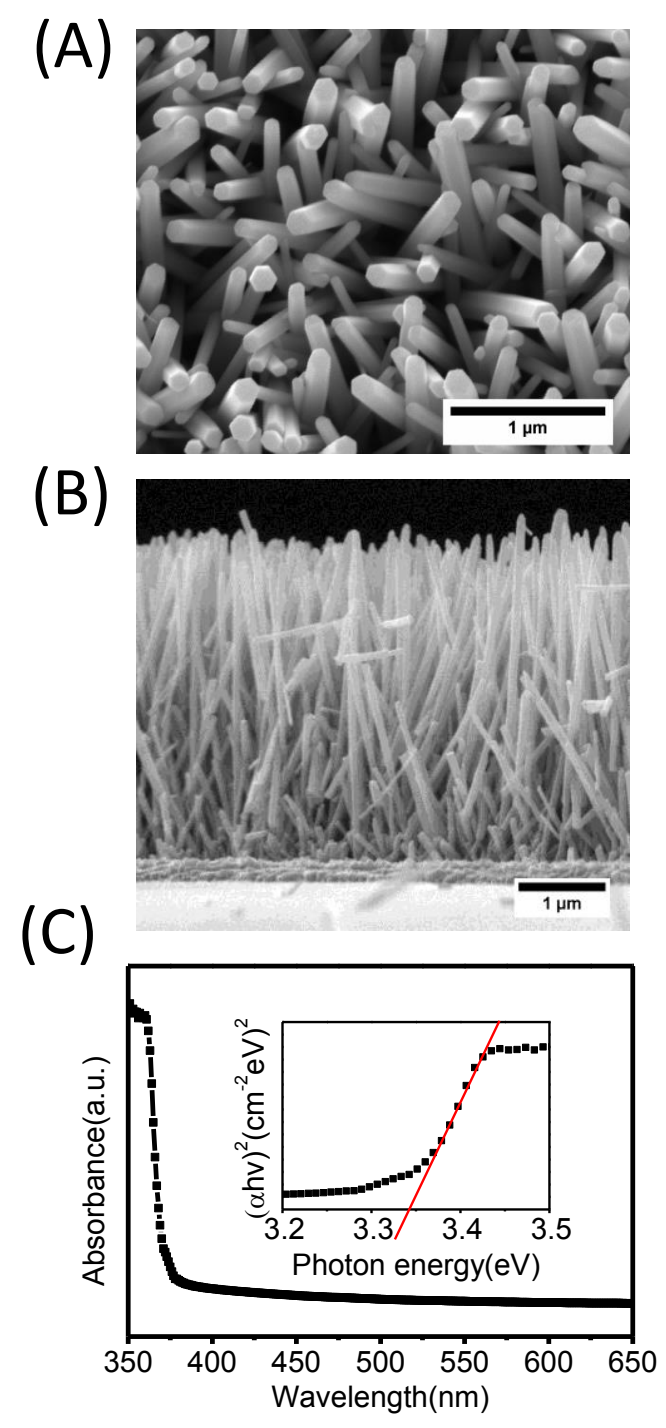

Figure 2. SEM images of ZnO nanorods (A) top view, (B) cross section; (C) UV-Vis spectrum and inset Tauc-plot.

\section{Linear sweep voltammetry at ZnO nanorods}

$\mathrm{ZnO}$ nanorods on FTO-coated glass substrates displayed significant photocurrents in linear sweep voltammetry (LSV) with chopped $405 \mathrm{~nm}$ diode laser illumination at anodic potentials $\geq+0.2 \mathrm{~V}$ vs. $\mathrm{Ag} / \mathrm{AgCl}$ (Figure 3). The photo-induced anodic current under illumination increased with the applied bias, while the change of the dark current was negligible. To make certain that the photocurrent originated from the ZnO nanorods, LSV was carried out under the same conditions on a bare FTO-coated glass substrate (Figure S-2)). The photocurrent in FTO was at nA level, which was $10^{3}$ times smaller than the 
photocurrent in $\mathrm{ZnO}$ and can be neglected.

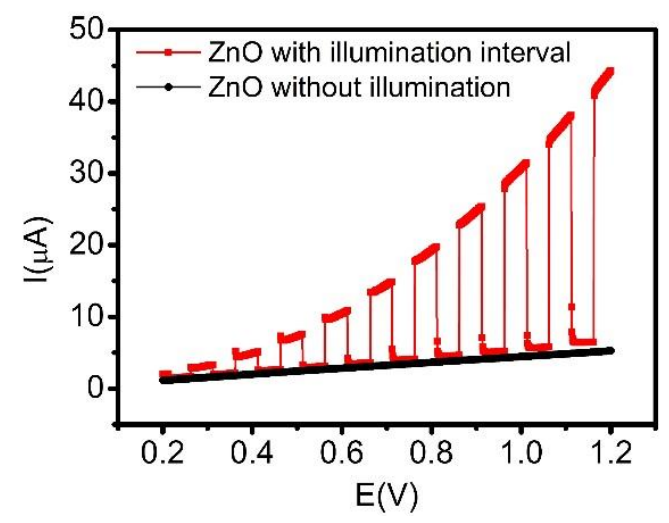

Figure 3 Linear sweep voltammetry of $\mathrm{ZnO}$ nanorods on FTO coated glass

An impedance spectrum of the $\mathrm{ZnO}$ nanorods in phosphate-buffered saline (PBS) was measured in the dark (Figures S-3(A) and (B)). A capacitance of $18 \mu \mathrm{F} / \mathrm{cm}^{2}$ in $\mathrm{ZnO}$ was obtained at zero bias, which was identified as the serial combination of the capacitances of the depletion layer and the electrical double layer. The capacitance decreased with increasing applied bias, as shown in Figure $\mathrm{S}-3(\mathrm{C})$, which indicated that the depletion layer $\left(\mathrm{C}_{\text {value }}=\right.$ $1.28 \mu \mathrm{F} / \mathrm{cm}^{2}$ at $1 \mathrm{~V}$ ) was dominant at high anodic voltages.

\section{LAPS and SPIM measurements}

AC photocurrent-voltage (I- $V$ ) characteristics of $\mathrm{ZnO}$ nanorods (Figure $4(\mathrm{~A})$ ) were measured with an unfocused laser modulated at $10 \mathrm{~Hz}$ in $\mathrm{pH} 7.4$ PBS using the LAPS setup shown in Figure 1. The photocurrent of $\mathrm{ZnO}$ nanorods increased with the applied bias and approached a plateau of $50 \mathrm{nA}$ at $1.8 \mathrm{~V}$. At higher voltages, the AC photocurrent could not be measured due to a large DC background current. Figure 4(B) shows the effect of the modulation frequency on the photocurrent at $1.5 \mathrm{~V}$; both photocurrent and dark current were measured from $10 \mathrm{~Hz}$ to $10 \mathrm{kHz}$. The photocurrent significantly decreased at frequencies greater than $100 \mathrm{~Hz}$ due to the low mobility of minority charge carriers in $\mathrm{ZnO}$, while the dark current, which is indicative of the noise level of the experimental setup, remained relatively constant. Consequently, the signal-to-noise ratio decreased with increasing frequency, and the 
photocurrent became unmeasurable at about $10 \mathrm{kHz}$. To ensure good sensitivity of local photocurrent measurements, a modulation frequency of $10 \mathrm{~Hz}$ and an applied bias of $1.5 \mathrm{~V}$ were selected for all LAPS measurements. The effect of the light intensity on the photocurrent was also studied (Figure S-4). At $1.5 \mathrm{~V}$, the photocurrent increased with increasing light intensity. The photocurrent was $390 \mathrm{nA}$ at the maximum intensity of $0.5 \mathrm{~mW}$. In this work, $10 \%$ of the maximum intensity $\left(0.05 \mathrm{~mW}\right.$ with an average irradiance of $\left.3.8 \mathrm{~mW} / \mathrm{cm}^{2}\right)$ was selected for LAPS measurements.

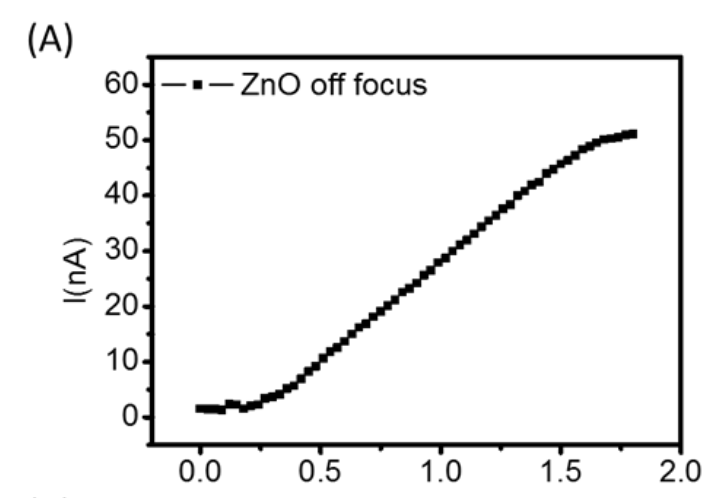

(B)

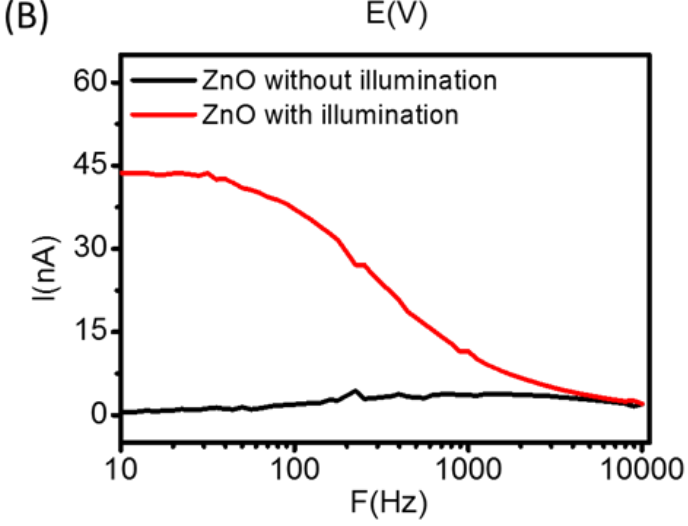

Figure 4 (A) LAPS I-V curves of $\mathrm{ZnO}$ nanorods in $\mathrm{pH} 7.4 \mathrm{PBS}$ buffer at $10 \mathrm{~Hz}$ with an unfocused laser beam (diameter of the light spot off focus $1.3 \mathrm{~mm}$ ), (B) the frequency dependence of $A C$ photocurrent and background $A C$ current in the dark.

A photocurrent image can be measured by LAPS with a focused laser beam. To find the focus, the distance between sample and microscope objective on the $Z$ axis was scanned in a $400 \mu \mathrm{m}$ range while measuring the photocurrent (Figure $5(A)$ ). In focus, the photocurrent reached a minimum as the electrode 
area for the photo-anodic process seen in the LSV measurements in Figure 3 was effectively reduced. Enhanced recombination of charge carriers is likely to have contributed to the decrease of the photocurrent in focus due to the high irradiance (irradiance is inversely proportional to the square of the laser spot diameter). The focused laser beam size was approximately $1 \mu \mathrm{m}$. The $\mathrm{I}-\mathrm{V}$ curve in focus (Figure $5(B)$ ) was shown to have a similar trend but a lower photocurrent compared to the one off focus (Figure $4(A)$ ).
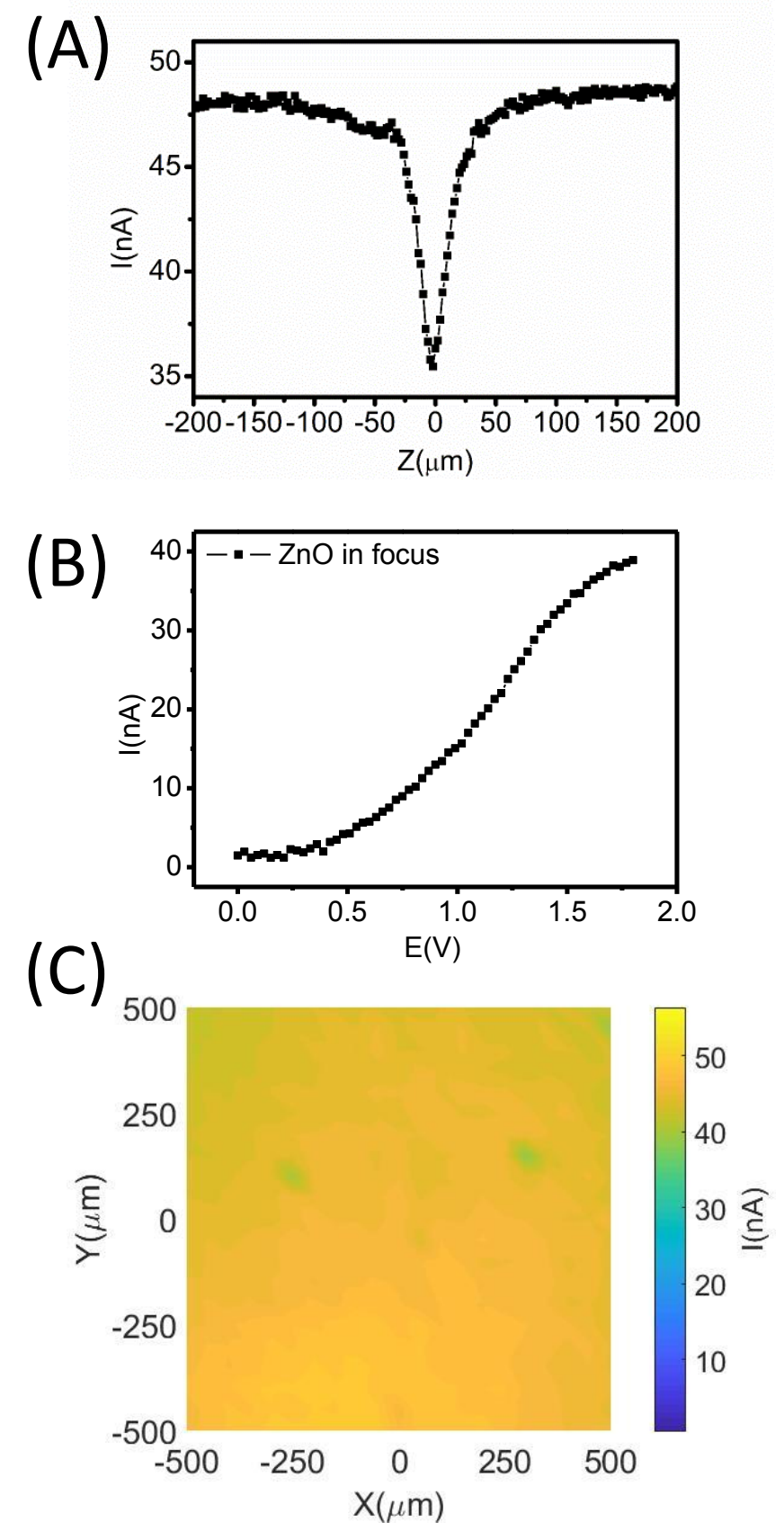
Figure 5. AC photocurrent measurements at $\mathrm{ZnO}$ nanorods at $10 \mathrm{~Hz}$ modulation frequency at 1.5V: (A) Z-axis line scan of photocurrent around the focus, (B) LAPS I-V curve in focus, (C) photocurrent area scan.

An AC photocurrent image of a selected area of $\mathrm{ZnO}$ nanorods recorded by LAPS (Figure $5(C)$ ) demonstrated a uniform photocurrent of $45.7 \pm 0.1 \mathrm{nA}$ with a focused laser beam at $10 \mathrm{~Hz}$ and an applied bias of $1.5 \mathrm{~V}$. The background photocurrent image of bare FTO-coated glass was measured under the same conditions (Figure S-5), which shows a photocurrent of less than $0.3 \mathrm{nA}$.

The effect of ZnO morphology on the device performance for LAPS imaging

The device performance of $\mathrm{ZnO}$ for LAPS imaging was investigated using two different morphologies, $\mathrm{ZnO}$ nanorods (see Figures $2(\mathrm{~A})$ and $(\mathrm{B})$ ) and a $\mathrm{ZnO}$ film with the same thickness grown at a higher concentration of the same precursor (Figure 6). In the film, $\mathrm{ZnO}$ formed columns with much larger diameters in a range of 0.3 to $0.9 \mu \mathrm{m}$, which were mostly fused together in a film-like structure as shown in the cross-sectional view (Figure 6(B)) with some gaps still visible in the top view (Figure 6(A)).

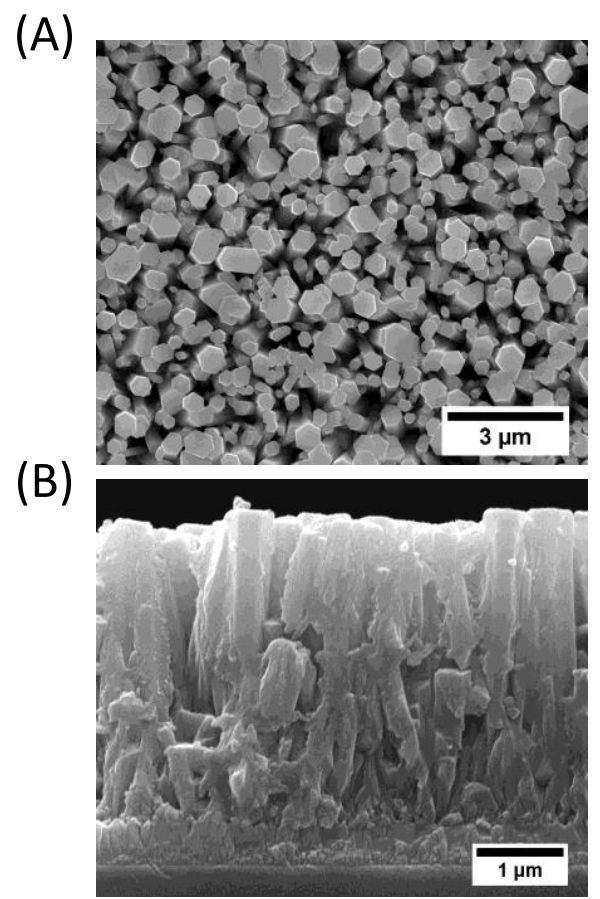


Figure 6 SEM images of the $\mathrm{ZnO}$ film (A) top view and (B) cross-section

Figures $7(A)$ and $(B)$ show photocurrent images with a PMMA dot on the surface of the $\mathrm{ZnO}$ for the nanorods and the film. The photocurrent measured on the uncoated areas of the $\mathrm{ZnO}$ was approximately five times larger on the nanorods ( $45.7 \pm 0.1 \mathrm{nA})$ than on the film $(9.2 \pm 0.2 \mathrm{nA})$. This can be explained with the significantly larger specific surface area of the nanorods compared to that of the film and represents a considerable advantage of nanorods in this type of measurement. The area covered with PMMA shows a significantly lower photocurrent than the uncovered area for both $\mathrm{ZnO}$ morphologies. The photocurrent contrast was ascribed to the high impedance of the PMMA dot on the surface. To measure the lateral resolution, photocurrent line scans with $500 \mathrm{~nm}$ step width across the edge of the PMMA dots were performed (Figure $7(\mathrm{C})$ ). The lateral resolution calculated from the full width at half-maximum (FWHM) of the first derivative of the line scans (Figure 7 (D)) was $3.0 \mu \mathrm{m}$ for the $\mathrm{ZnO}$ nanorods and $12 \mu \mathrm{m}$ for the $\mathrm{ZnO}$ film. The diffusion length of minority charge carriers in bulk n-type $\mathrm{ZnO}$ typically assumes values of $130-440 \mathrm{~nm},{ }^{39}$ i.e. the lateral diffusion of charge carriers cannot be responsible for the difference in resolution between nanorods and film. As the features in the film are larger than the wavelength of light used for imaging, it is likely that light scattering is causing a significant degradation of the resolution. In contrast, the $\mathrm{ZnO}$ nanorods have diameters significantly smaller than the wavelength of light making light scattering effects negligible, thereby resulting in better lateral resolution. With a lateral resolution of $3.0 \mu \mathrm{m}$, this abundant metal oxide has great potential to be applied in biological imaging. 
(A)

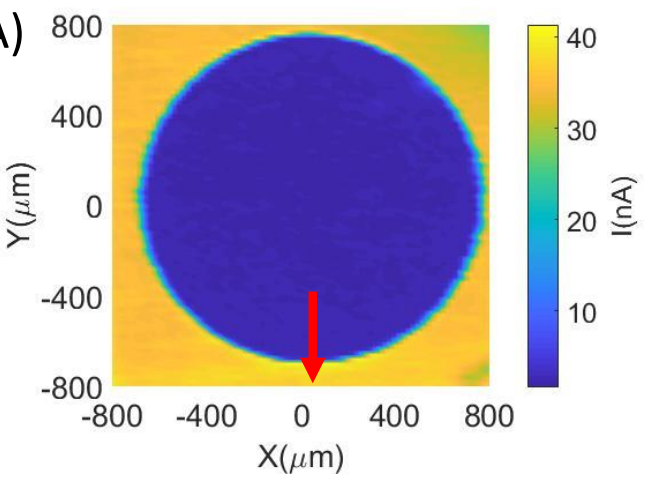

(C)

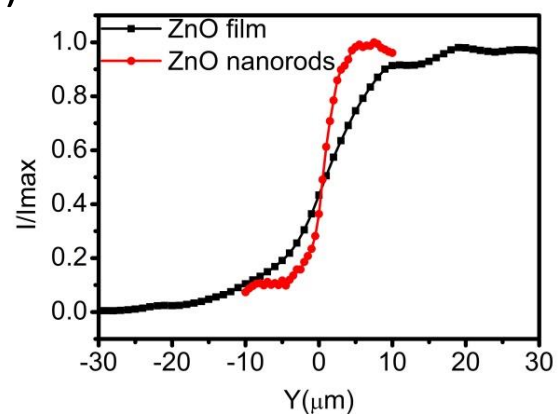

(B)

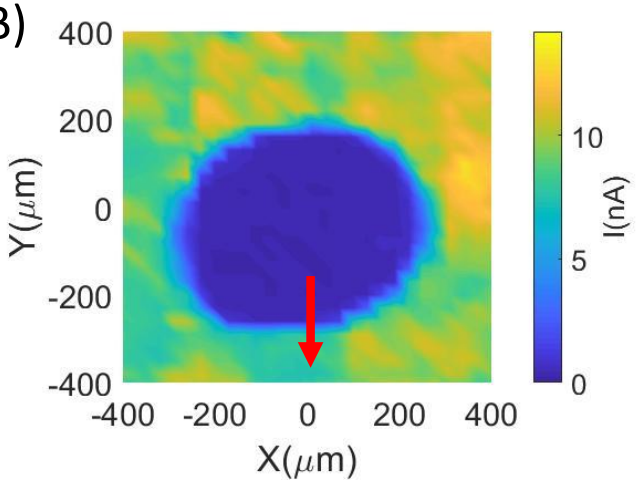

(D)

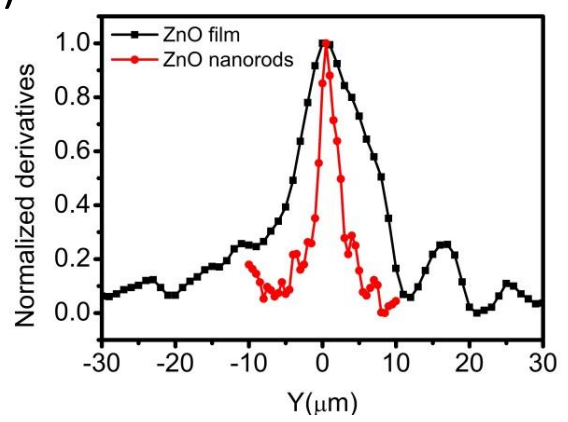

Figure 7. Photocurrent images of a PMMA dot on $\mathrm{ZnO}(A)$ nanorods and $(B)$ film, in which the red arrows indicate the line scan direction; (C) Y-axis photocurrent line scans across the edge of the PMMA dots; $(D)$ the first derivative of panel $(C)$.

\section{Sensor applications of $\mathrm{ZnO}$ nanorods}

To assess the feasibility of using $\mathrm{ZnO}$ nanorods as a substrate for LAPS in practical applications, its $\mathrm{pH}$ sensitivity was tested, and the possibility of using the new substrate in a biosensor format was investigated. Figure 8 displays the $\mathrm{pH}$ sensitivity of $\mathrm{ZnO}$ nanorods in a range of phosphate buffer solutions (pH 5-9) with $0.1 \mathrm{M} \mathrm{KCl}$ using an unfocused laser to illuminate a sample area of $1.3 \mathrm{~mm}$ in diameter. The $I-V$ curve shifted towards higher potentials with decreasing $\mathrm{pH}$, which is typical for an n-type semiconductor. ${ }^{21}$ As there is no insulator present on the $\mathrm{ZnO}$ nanorods, the $\mathrm{pH}$ sensitivity could originate from the surface potential as in classical LAPS, but could also be affected by the anodic process (see Figure 2(A)), which can be ascribed to the oxidation of $\mathrm{OH}^{-}$, and would, therefore, not be expected to follow the Nernst equation. At a constant photocurrent of $40 \mathrm{nA}, \mathrm{ZnO}$ was observed to have an average 
sensitivity of $53 \mathrm{mV} / \mathrm{pH}$ by linear fitting with R-square of 0.96 (inset Figure 8). This shows $\mathrm{ZnO}$ to be a promising sensing material for a $\mathrm{pH}$ imaging sensor as well as the potential for other biochemical characterization with LAPS.

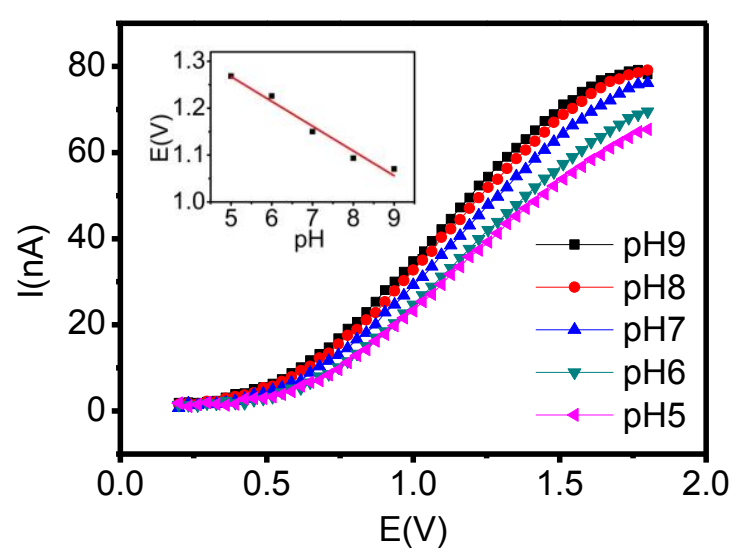

Figure 8. LAPS I-V curves of $\mathrm{ZnO}$ nanorods in different $\mathrm{pH}$ solutions, inset is the $\mathrm{pH}$ sensitivity.

Previous research has developed biosensors for the detection of enzyme activities based on the degradation of thin polymer films. Degradation of the polymer films has been monitored by using techniques such as surface plasmon resonance $(\mathrm{SPR})^{37,40}$, quartz crystal microbalance $(\mathrm{QCM})^{41,42}$, impedance measurements and $\mathrm{SPIM}^{41,43-46}$. In this work, a poly(ester amide) for the detection of a-chymotrypsin was deposited onto the $\mathrm{ZnO}$ nanorods by drop-coating $1 \mu \mathrm{L}$ of poly(ester amide) $(200 \mathrm{mg} / \mathrm{ml}$ in chloroform). The polymer dot on the $\mathrm{ZnO}$ nanorods substrate is clearly visible in the photocurrent image in Figure $9(A)$ and the corresponding phase image in Figure 9(B). As the phase between photocurrent and light intensity proved to be more stable than the photocurrent, the polymer degradation was monitored by recording phase images (Figures $9(C)-(F)$ ). The area of the film decreased with time; approximately $60 \%$ of the polymer had been degraded after $2 \mathrm{~h}$, and the polymer completely disappeared after $6 \mathrm{~h}$. The area of the polymer dot in the phase images was calculated using ImageJ and plotted versus time (Figure 10). With the assumption that the polymer was uniform on the $\mathrm{ZnO}$ nanorods, the average degradation rate of the poly(ester amide) was estimated to be 29 
$\mu \mathrm{g} / \mathrm{h}$ in the presence of $100 \mu \mathrm{M}$ a-chymotrypsin. This demonstrates the suitability of LAPS imaging using $\mathrm{ZnO}$ nanorods for the interrogation of biosensor arrays and for real-time imaging of biological processes. The low cost of $\mathrm{ZnO}$ and an easily scalable solution deposition technique make this a promising substrate for disposable biosensors.
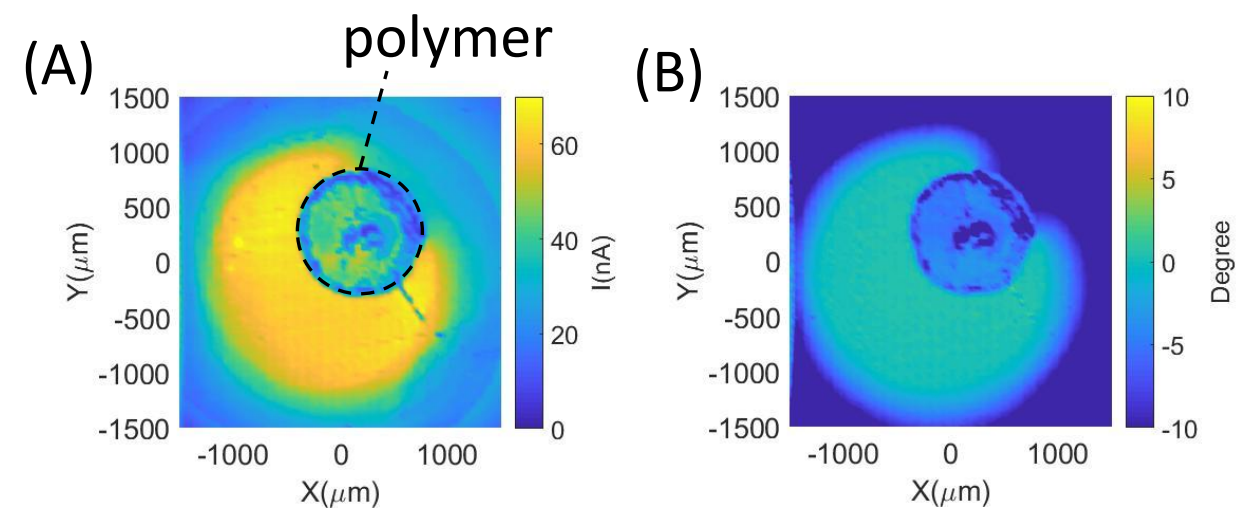

(C)

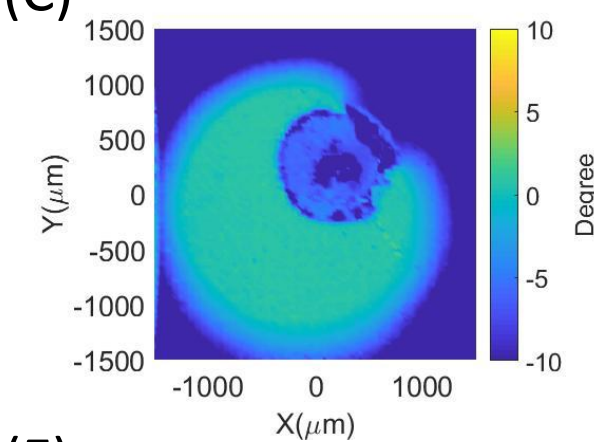

(E)
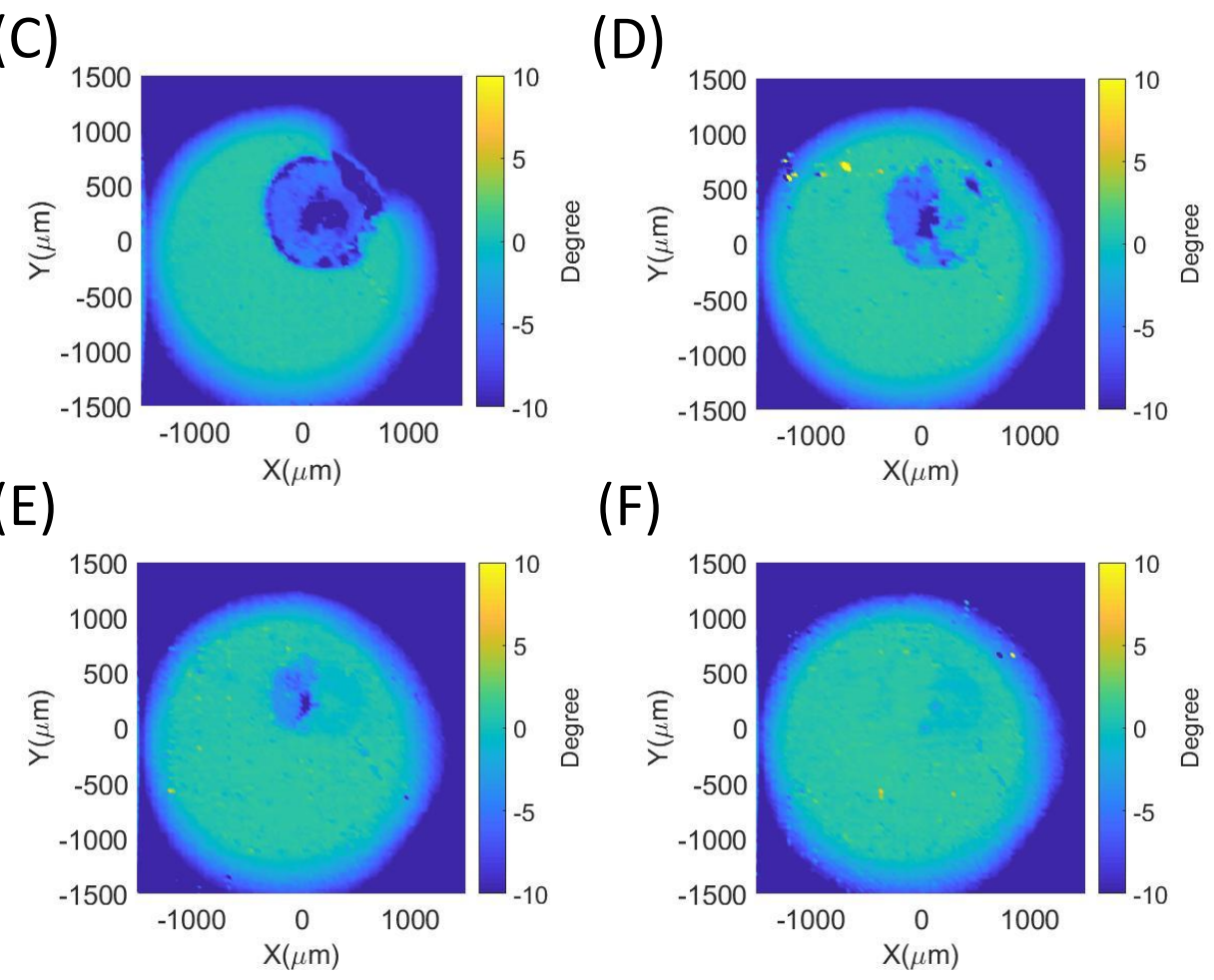

(F)

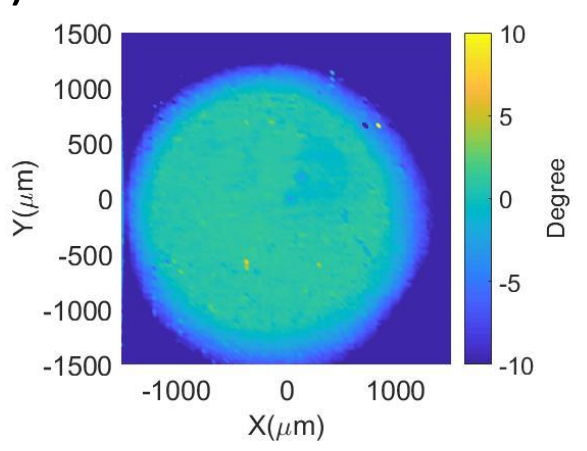

Figure 9. (A) Photocurrent image and (B) phase image of poly(ester amide) on $\mathrm{ZnO}$ nanorods in $\mathrm{pH} 7.3$ buffer. Phase images taken at (C) $0 \mathrm{~h}$, (D) $2 \mathrm{~h}$, (E) $4 \mathrm{~h}$ and (F) $6 \mathrm{~h}$ after adding $100 \mu \mathrm{M}$-chymotrypsin into $\mathrm{pH} 7.3$ buffer solution. 


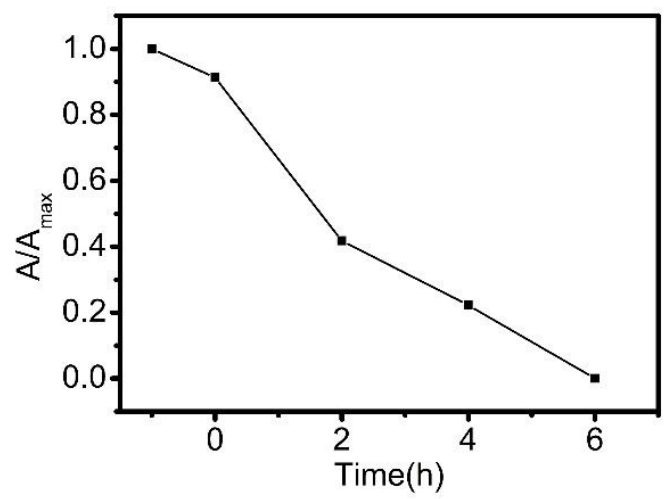

Figure 10. Area of poly(ester amide) degradation by $100 \mu \mathrm{M} \alpha$-chymotrypsin. The enzyme was added at $t=0$.

\section{Conclusions}

$\mathrm{ZnO}$ nanorods synthesized using a simple aqueous solution method on FTO-coated glass were found to be uniform and well-oriented in the c-axis with a high aspect ratio of 51 . The nanostructured semiconductor was shown to be suitable for photocurrent imaging with LAPS without the need of an insulator. Photocurrent images of a PMMA dot deposited on $\mathrm{ZnO}$ nanorods and $\mathrm{ZnO}$ films showed that the 1D substrate has the advantage of higher photocurrents and better resolution than a film of the same thickness. $\mathrm{ZnO}$ nanorods displayed a pH sensitivity of $53 \mathrm{mV} / \mathrm{pH}$ in a pH range from 5-9 and were shown to be suitable for use in a biosensor format aimed at the detection of enzymes by monitoring the degradation a polymer film. The sensor showed sufficient stability for monitoring the polymer degradation over $6 \mathrm{~h}$. The large photocurrents paired with good lateral resolution and $\mathrm{pH}$ sensitivity make $\mathrm{ZnO}$ nanorods a promising sensor substrate for biosensing and bioimaging applications. The successful demonstration of the suitability of nanostructured semiconductors without an insulator as substrates for LAPS greatly expands the range semiconductor materials that can be used in this imaging technique, making it more attractive for general use.

\section{Acknowledgements}

The authors are grateful to the Biotechnology and Biological Sciences 
Research Council (BBSRC) of UK for providing research funding (BB/ P026788/1) to the EU for providing a Marie Skłodowska-Curie Individual Fellowship (H2020-MSCA-IF-2014-660489) and to the China Scholarship Council for providing a PhD studentship to Y.T. The authors thank Thermo Scientific for carrying out the XPS measurements.

\section{Supporting information}

- Figure S-1 O 1s XPS spectrum of $\mathrm{ZnO}$ nanorods

- Figure S-2 LSV measurement of bare FTO

- Figure S-3 Impedance spectra and capacitance-voltage curve of $\mathrm{ZnO}$ nanorods

- Figure S-4 Light intensity dependency of the photocurrent

- Figure S-5 Photocurrent imaging of bare FTO by LAPS

\section{References}

(1) Owicki, J. C.; Bousse, L. J.; Hafeman, D. G.; Kirk, G. L.; Olson, J. D.; Wada, H. G.; Parce, J. W. The Light-Addressable Potentiometric Sensor: Principles and Biological Applications. Annu. Rev. Biophys. Biomol. Struct. 1994, 23 (1), 87-114.

(2) Hafeman, D. G.; Parce, J. W.; Mcconnell, H. M. Light-Addressable Potentiometric. Science 1988, 240 (7), 1182-1185.

(3) Wu, F.; Campos, I.; Zhang, D.-W.; Krause, S. Biological Imaging Using Light-Addressable Potentiometric Sensors and Scanning Photo-Induced Impedance Microscopy. Proc. R. Soc. A Math. Phys. Eng. Sci. 2017, 473 (2201), 1-20.

(4) Pohanka, M.; Leuchter, J. Biosensors Based on Semiconductors, a Review. Int. J. Electrochem. Sci. 2017, 12 (7), 6611-6621.

(5) Werner, C. F.; Miyamoto, K. ichiro; Wagner, T.; Schöning, M. J.; Yoshinobu, T. Lateral Resolution Enhancement of Pulse-Driven Light-Addressable Potentiometric Sensor. Sens. Actuators, B Chem. 
2017, 248, 961-965.

(6) Liang, J.; Zhu, N.; Li, S.; Jia, H.; Xue, Y.; Cui, L.; Huang, Y.; Li, G. Light-Addressable Potentiometric Sensor with Gold Nanoparticles Enhancing Enzymatic Silver Deposition for 1,5-Anhydroglucitol Determination. Biochem. Eng. J. 2017, 123, 29-37.

(7) Shaibani, P. M.; Etayash, H.; Naicker, S.; Kaur, K.; Thundat, T. Metabolic Study of Cancer Cells Using a PH Sensitive Hydrogel Nanofiber Light Addressable Potentiometric Sensor. ACS Sensors 2017, 2 (1), 151-156.

(8) Zhang, D.-W.; Wu, F.; Wang, J.; Watkinson, M.; Krause, S. Image Detection of Yeast Saccharomyces Cerevisiae by Light-Addressable Potentiometric Sensors (LAPS). Electrochem. commun. 2016, 72, 4145.

(9) Shaibani, P. M.; Jiang, K.; Haghighat, G.; Hassanpourfard, M.; Etayash, H.; Naicker, S.; Thundat, T. The Detection of Escherichia Coli (E. Coli) with the $\mathrm{PH}$ Sensitive Hydrogel Nanofiber-Light Addressable Potentiometric Sensor (NF-LAPS). Sens. Actuators, B Chem. 2016, 226, 176-183.

(10) Wang, J.; Campos, I.; Wu, F.; Zhu, J.; Sukhorukov, G. B.; Palma, M.; Watkinson, M.; Krause, S. The Effect of Gold Nanoparticles on the Impedance of Microcapsules Visualized by Scanning Photo-Induced Impedance Microscopy. Electrochim. Acta 2016, 208, 39-46.

(11) Yoshinobu, T.; Iwasaki, H.; Ui, Y.; Furuichi, K.; Ermolenko, Y.; Mourzina, Y.; Wagner, T.; Näther, N.; Schöning, M. J. The Light-Addressable Potentiometric Sensor for Multi-lon Sensing and Imaging. Methods. 2005,94-102.

(12) Zhang, W.; Xu, Y.; Tahir, H. E.; Zou, X.; Wang, P. Rapid and Wide-Range Determination of $\mathrm{Cd}(\mathrm{II}), \mathrm{Pb}(\mathrm{II}), \mathrm{Cu}(\mathrm{II})$ and $\mathrm{Hg}(\mathrm{II})$ in Fish Tissues Using Light Addressable Potentiometric Sensor. Food Chem. 2017, 221, 541547.

(13) Chen, L.; Zhou, Y.; Jiang, S.; Kunze, J.; Schmuki, P.; Krause, S. High 
Resolution LAPS and SPIM. Electrochem. commun. 2010, 12 (6), 758760 .

(14) Zhang, D.-W.; Papaioannou, N.; David, N. M.; Luo, H.; Gao, H.; Tanase, L. C.; Degousée, T.; Samorì, P.; Sapelkin, A.; Fenwick, O.; et al. Photoelectrochemical Response of Carbon Dots (CDs) Derived from Chitosan and Their Use in Electrochemical Imaging. Mater. Horizons 2018, 5 (3), 423-428.

(15) Guo, Y.; Miyamoto, K.; Wagner, T.; Schöning, M. J.; Yoshinobu, T. Theoretical Study and Simulation of Light-Addressable Potentiometric Sensors. Phys. status solidi 2014, 211 (6), 1467-1472.

(16) Guo, Y.; Miyamoto, K.-I.; Wagner, T.; Schöning, M. J.; Yoshinobu, T. Device Simulation of the Light-Addressable Potentiometric Sensor for the Investigation of the Spatial Resolution. Sens. Actuators B. Chem. 2014, 204, 659-665.

(17) Moritz, W.; Yoshinobu, T.; Finger, F.; Krause, S.; Martin-Fernandez, M.; Schöning, M. J. High Resolution LAPS Using Amorphous Silicon as the Semiconductor Material. Sens. Actuators B Chem. 2004, 103, 436-441.

(18) Das, A.; Das, A.; Be, L.; Chao, C.; Lai, S.; Ming, R.; Fu, L.; Chu, C.; Heng, Y.; Lee, L.; et al. GaN Thin Film Based Light Addressable Potentiometric Sensor for PH Sensing Application. Appl. Phys. Express 2013, 036601 (6), 1-3.

(19) Yang, C. M.; Chiang, T. W.; Yeh, Y. T.; Das, A.; Lin, Y. T.; Chen, T. C. Sensing and $\mathrm{PH}-$ Imaging Properties of Niobium Oxide Prepared by Rapid Thermal Annealing for Electrolyte-Insulator-Semiconductor Structure and Light-Addressable Potentiometric Sensor. Sens. Actuators, B Chem. 2015, 207, 858-864.

(20) Suzurikawa, J.; Nakao, M.; Jimbo, Y.; Kanzaki, R.; Takahashi, H. A Light Addressable Electrode with a $\mathrm{TiO} 2$ Nanocrystalline Film for Localized Electrical Stimulation of Cultured Neurons. Sens. Actuators, B Chem. 2014, 192, 393-398. 
(21) Zhang, D.-W.; Wu, F.; Krause, S. LAPS and SPIM Imaging Using ITO-Coated Glass as the Substrate Material. Anal. Chem. 2017, 89 (15), 8129-8133.

(22) Shoaee, S.; Briscoe, J.; Durrant, J. R.; Dunn, S. Acoustic Enhancement of Polymer/ZnO Nanorod Photovoltaic Device Performance. Adv. Mater. 2014, 26 (2), 263-268.

(23) Jalali, N.; Woolliams, P.; Stewart, M.; Weaver, P. M.; Cain, M. G.; Dunn, S.; Briscoe, J. Improved Performance of $\mathrm{P}-\mathrm{n}$ Junction-Based $\mathrm{ZnO}$ Nanogenerators through CuSCN-Passivation of ZnO Nanorods. J. Mater. Chem. A 2014, 2 (28), 10945-10951.

(24) Hatch, S. M.; Briscoe, J.; Dunn, S. A Self-Powered ZnO-Nanorod/CuSCN UV Photodetector Exhibiting Rapid Response. Adv. Mater. 2013, 25 (6), 867-871.

(25) Modaresinezhad, E.; Darbari, S. Realization of a Room-Temperature/Self-Powered Humidity Sensor, Based on $\mathrm{ZnO}$ Nanosheets. Sens. Actuators, B Chem. 2016, 237, 358-366.

(26) Wen, Z.; Zhu, L.; Zhang, Z.; Ye, Z. Fabrication of Gas Sensor Based on Mesoporous Rhombus-Shaped ZnO Rod Arrays. Sens. Actuators, $B$ Chem. 2015, 208, 112-121.

(27) Hoffmann, M. W. G.; Mayrhofer Dr, L.; Casals Dr, O.; Caccamo, L.; Hernez-Ramirez, F.; Lilienkamp, G.; Daum, W.; Moseler, M.; Waag, A.; Shen, H.; et al. A Highly Selective and Self-Powered Gas Sensor via Organic Surface Functionalization of $\mathrm{p}-\mathrm{Si} / \mathrm{n}-\mathrm{ZnO}$ Diodes. Adv. Mater. 2014, 26 (47), 8017-8022.

(28) Xu, C. X.; Yang, C.; Gu, B. X.; Fang, S. J. Nanostructured ZnO for Biosensing Applications. Chinese Sci. Bull. 2013, 58 (21), 2563-2566.

(29) Arya, S. K.; Saha, S.; Ramirez-Vick, J. E.; Gupta, V.; Bhansali, S.; Singh, S. P. Recent Advances in ZnO Nanostructures and Thin Films for Biosensor Applications: Review. Anal. Chim. Acta 2012, 737, 1-21. 
(30) Georgekutty, R.; Seery, M. K.; Pillai, S. C. A Highly Efficient Ag-ZnO Photocatalyst: Synthesis, Properties, and Mechanism. J. Phys. Chem. C 2008, 112 (35), 13563-13570.

(31) Qin, H.; Li, W.; Xia, Y.; He, T. Photocatalytic Activity of Heterostructures Based on ZnO and N-Doped ZnO. ACS Appl. Mater. Interfaces 2011, 3 (8), 3152-3156.

(32) Janotti, A.; Van De Walle, C. G. Native Point Defects in ZnO. Phys. Rev. B - Condens. Matter Mater. Phys. 2007, 76 (16), 165202.

(33) Janotti, A.; Van de Walle, C. G. Fundamentals of Zinc Oxide as a Semiconductor. Reports Prog. Phys. 2009, 72 (12), 126501.

(34) Tu, Y.; Chen, S.; Li, X.; Gorbaciova, J.; Gillin, W. P.; Krause, S.; Briscoe, J. Control of Oxygen Vacancies in $\mathrm{ZnO}$ Nanorods by Annealing and Their Influence on ZnO/PEDOT:PSS Diode Behaviour. J. Mater. Chem. C 2018, 6 (7), 1815-1821.

(35) Xu, J.-Q.; Duo, H.-H.; Zhang, Y.-G.; Zhang, X.-W.; Fang, W.; Liu, Y.-L.; Shen, A.-G.; Hu, J.-M.; Huang, W.-H. Photochemical Synthesis of Shape-Controlled Nanostructured Gold on Zinc Oxide Nanorods as Photocatalytically Renewable Sensors. Anal. Chem. 2016, 88 (7), 37893795.

(36) Law, M.; Greene, L. E.; Johnson, J. C.; Saykally, R.; Yang, P. Nanowire Dye-Sensitized Solar Cells. Nat. Mater. 2005, 4 (6), 455-459.

(37) Sumner, C.; Sabot, A.; Turner, K.; Krause, S. A Transducer Based on Enzyme-Induced Degradation of Thin Polymer Films Monitored by Surface Plasmon Resonance. Anal. Chem. 2000, 72 (21), 5225-5232.

(38) Kotsis, K.; Staemmler, V. Ab Initio Calculations of the O1s XPS Spectra of $\mathrm{ZnO}$ and $\mathrm{Zn}$ Oxo Compounds. Phys. Chem. Chem. Phys. 2006, 8 (13), 1490-1498.

(39) Soudi, A.; Dhakal, P.; Gu, Y. Diameter Dependence of the Minority Carrier Diffusion Length in Individual ZnO Nanowires. Appl. Phys. Lett. 
2010, 96 (25), 253115.

(40) Shinozaki, Y.; Kikkawa, Y.; Sato, S.; Fukuoka, T.; Watanabe, T.; Yoshida, S.; Nakajima-Kambe, T.; Kitamoto, H. K. Enzymatic Degradation of Polyester Films by a Cutinase-like Enzyme from Pseudozyma Antarctica: Surface Plasmon Resonance and Atomic Force Microscopy Study. Appl. Microbiol. Biotechnol. 2013, 97 (19), 8591-8598.

(41) Sabot, A.; Krause, S. Simultaneous Quartz Crystal Microbalance Impedance and Electrochemical Impedance Measurements. Investigation into the Degradation of Thin Polymer Films. Anal. Chem. 2002, 74 (14), 3304-3311.

(42) Suchy, M.; Linder, M. B.; Tammelin, T.; Campbell, J. M.; Vuorinen, T.; Kontturi, E. Quantitative Assessment of the Enzymatic Degradation of Amorphous Cellulose by Using a Quartz Crystal Microbalance with Dissipation Monitoring. Langmuir 2011, 27 (14), 8819-8828.

(43) Biela, A.; Watkinson, M.; Meier, U. C.; Baker, D.; Giovannoni, G.; Becer, C. R.; Krause, S. Disposable MMP-9 Sensor Based on the Degradation of Peptide Cross-Linked Hydrogel Films Using Electrochemical Impedance Spectroscopy. Biosens. Bioelectron. 2015, 68, 660-667.

(44) Zhou, Y.; Jiang, S.; Krause, S.; Chazalviel, J.-N. Biosensor Arrays Based on the Degradation of Thin Polymer Films Interrogated by Scanning Photoinduced Impedance Microscopy. Anal. Chem. 2007, 79 (23), 8974-8978.

(45) Siqueira, J. R.; Maki, R. M.; Paulovich, F. V; Werner, C. F.; Poghossian, A.; de Oliveira, M. C. F.; Zucolotto, V.; Oliveira, O. N.; Schöning, M. J. Use of Information Visualization Methods Eliminating Cross Talk in Multiple Sensing Units Investigated for a Light-Addressable Potentiometric Sensor. Anal. Chem. 2010, 82 (1), 61-65.

(46) Keusgen, M.; Jünger, M.; Krest, I.; Schöning, M. J. Biosensoric Detection of the Cysteine Sulphoxide Alliin. Sens. Actuators B Chem. 2003, 95 (1-3), 297-302. 
For TOC only

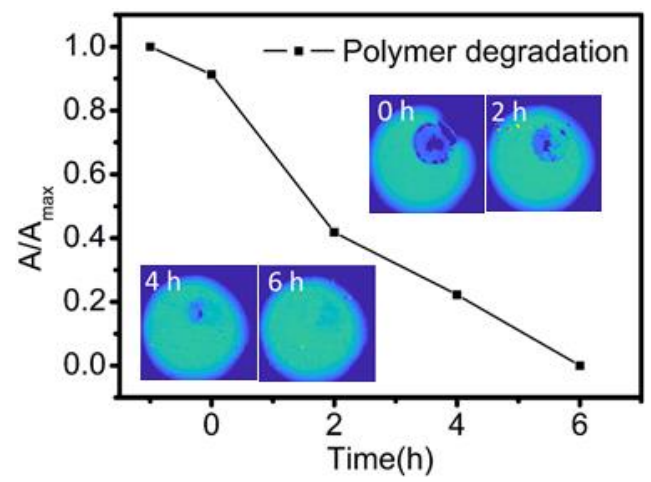

